\title{
GUT MICROBIAL-DERIVED SHORT-CHAIN FATTY ACIDS AND BONE: A POTENTIAL ROLE IN FRACTURE HEALING
}

\author{
A. Wallimann ${ }^{1,2}$, W. Magrath ${ }^{1}$, K. Thompson ${ }^{1}$, T.F. Moriarty ${ }^{1}$, R.G. Richards ${ }^{1}$, C.A. Akdis ${ }^{2}$, L. O’Mahony ${ }^{3}$ \\ and C.J. Hernandez $z^{4,5, *}$ \\ ${ }^{1} \mathrm{AO}$ Research Institute Davos, Davos, Switzerland \\ ${ }^{2}$ Swiss Institute for Allergy and Asthma Research Davos (SIAF), University of Zurich, Switzerland \\ ${ }^{3}$ Department of Medicine and School of Microbiology, APC Microbiome Ireland, University College Cork, \\ College Road, Cork, Ireland \\ ${ }^{4}$ Sibley School of Mechanical and Aerospace Engineering, Cornell University, Ithaca, NY, USA \\ ${ }^{5}$ Hospital for Special Surgery, New York, NY, USA
}

\begin{abstract}
Bone healing complications such as delayed healing or non-union affect 5-10\% of patients with a longbone fracture and lead to reduced quality of life and increased health-care costs. The gut microbiota and the metabolites they produce, mainly short-chain fatty acids (SCFAs), have been shown to impact nearly all organs of the human body including bone. SCFAs show broad activity in positively influencing bone healing outcomes either by acting directly on cell types involved in fracture healing, such as osteoblasts, osteoclasts, chondrocytes and fibroblasts, or indirectly, by shaping an appropriate anti-inflammatory and immune regulatory response. Due to the ability of SCFAs to influence osteoblast and osteoclast differentiation, SCFAs may also affect the integration of orthopaedic implants in bone. In addition, SCFA-derivatives have already been used in a variety of tissue engineering constructs to reduce inflammation and induce bone tissue production. The present review summarises the current knowledge on the role of the gut microbiota, in particular through the action of SCFAs, in the individual stages of bone healing and provides insights into how SCFAs may be utilised in a manner beneficial for fracture healing and surgical reconstruction.
\end{abstract}

Keywords: Bone fracture, gut microbiota, short-chain fatty acids (SCFAs), osteoclasts, osteoblasts, tissue engineering constructs, osseointegration.

*Address for correspondence: Christopher J. Hernandez, 355 Upson Hall, Cornell University, Ithaca, NY 14853, USA.

Telephone number: +1 6072555129 Fax number: +16072551222 Email: cjh275@cornell.edu

Copyright policy: This article is distributed in accordance with Creative Commons Attribution Licence (http://creativecommons.org/licenses/by-sa/4.0/).

\begin{tabular}{|c|c|c|c|}
\hline & List of Abbreviations & DCs & dendritic cells \\
\hline & & DMOG & dimethyloxalylglycine \\
\hline Akt & protein kinase B & ECM & extracellular matrix \\
\hline Aldh1A2 & aldehyde dehydrogenase 1 family & eNOS & endothelial nitric oxide synthase \\
\hline & member A2 & ERK & extracellular-signal-regulated kinase \\
\hline ALP & alkaline phosphatase & FFAR & free fatty acid receptors \\
\hline apoE & apolipoprotein E & FMT & faecal microbiota transplantation \\
\hline BM-MSCs & bone-marrow-derived MSCs & GAG & glycosaminoglycan \\
\hline BMP-2 & bone morphogenic protein-2 & GPR & G-protein-coupled receptor \\
\hline CCL2/MCP-1 & monocyte chemoattractant protein-1 & H3К9 & histone 3 lysine 9 \\
\hline CD & cluster of differentiation & HDAC & histone deacetylase \\
\hline COL2A1 & collagen type 2 alpha 1 chain & HIV & human immunodeficiency virus \\
\hline COX-2 & cyclooxygenase-2 & HUVECs & human umbilical vein endothelial \\
\hline $\mathrm{CT}$ & computed tomography & & cells \\
\hline CTLA4 & cytotoxic T-lymphocyte-associated & IDO1 & indoleamine 2,3-dioxygenase 1 \\
\hline & protein 4 & $\mathrm{IFN} \gamma$ & interferon gamma \\
\hline CTX-1 & C-terminal telopeptide & IGF-1 & insulin-like growth factor 1 \\
\hline
\end{tabular}


IL

Jam3

JNK

Mac-1

MAMPs

MAPK

MCT1

MMP

MSCs

mTORC1

$N F \kappa B$

NSE

OPG

PAP

PBH

PECAM-1

PHA

PI3K

PPAR $\gamma$

PTH

RANKL

Runx2

SCFAs

Slc16a1

Slc5a8

SMCT1

Sox9

sPG

STAT6

t-PA

TGF- $\beta$

Th

Tjp1

TNF $\alpha$

TRAP

Treg

TSA

VCAM-1

VEGF interleukin

junctional adhesion molecule $\mathrm{C}$

c-Jun N-terminal kinase

macrophage- 1 antigen

microbe-associated molecular

patterns

mitogen-activated protein kinase

monocarboxylate transporter 1

matrix metalloproteinase

mesenchymal stromal cells

mammalian target of rapamycin

complex 1

nuclear factor kappa B

non-specific elastase

osteoprotegerin

perioperative antibiotic prophylaxis

poly(beta-hydroxybutyrate)

platelet endothelial cell adhesion

molecule

polyhydroxyalkanoate

phosphoinositide 3-kinase

peroxisome proliferator-activated

receptor gamma

parathyroid hormone

receptor activator of $\mathrm{NF} \kappa \mathrm{B}$

Runt-related transcription factor 2

short-chain fatty acids

solute carrier family 16 member 1

solute carrier family 5 member 8

sodium monocarboxylate transporter

1

sex-determining region $\mathrm{Y}$ box 9

sulphated proteoglycan

signal transducer and activator of transcription 6

tissue-type plasminogen-activator

transforming growth factor beta

$\mathrm{T}$ helper cell

tight junction protein $\mathrm{ZO}-1$

tumour necrosis factor alpha

tartrate-resistant acid phosphatase

regulatory $\mathrm{T}$ cell

Trichostatin A

vascular cell adhesion molecule-1

vascular endothelial growth factor

\section{Introduction}

The gut microbiota and its role in health and disease The human microbiota consists of bacteria, viruses and fungi. The activity of the microbiome has a profound influence on many aspects of human physiology and metabolism, which is perhaps not surprising as the total number of microbial genes within the gut greatly outnumbers those of all known human genes by a factor of 100:1 (Baquero and Nombela, 2012; Hagan et al., 2019). The effects of the gut microbiome on bone have been suggested for some time. Early studies from the 1950s examining the use of oral antibiotics in farm animals revealed a large increase in bone growth rates and overall bone size attributed to changes to the gut microbiota that enhanced caloric absorption throughout growth (Jukes and Williams, 1953; Rusoff LL, 1954; Yacowitz, 1954). However, precise mechanisms for this observation have not been clearly established.

Investigating the effects of the gut microbiome on host physiology was hampered in these early studies due to technical limitations in culturing and characterising the variety of microbes that inhabit the gut. The advent of next generation sequencing in the 2000s overcame these limitations and enabled detailed investigation of the effects of the gut microbiome on host physiology.

Within the gut, commensal bacteria and host cells interact in a manner often beneficial to the host. The benefits imparted by the microbiome to the host include the maturation of the intestinal immune system through interactions with macrophages and DCs as well as the maintenance of a healthy gut barrier through induction of mucus production and the provision of nutrients to intestinal epithelial cells (Lin and Zhang, 2017; Shi et al., 2017; Wells et al., 2017). However, modifications to the gut microbial community can interrupt the beneficial relationship between microbes and the host and contribute to the pathogenesis or progression of morbidities, including inflammatory-bowel disease, colorectal cancer, cardiovascular diseases, asthma, Alzheimer's disease and rheumatoid arthritis, amongst others (Shreiner et al., 2015).

\section{The interaction of the gut microbiota with bone}

Modifications to the gut microbiota can influence both the biology and material properties of bone and are implicated in bone-associated pathologies such as osteoporosis and osteoarthritis (Jones et al., 2018; Li et al., 2019; Xu et al., 2017; Zhang et al., 2018). Changes to the gut microbiota can also influence bone metabolism and bone mineral absorption (Hernandez et al., 2016). Animal models indicate that the absence of a gut microbiota leads to changes in bone remodelling, trabecular bone mineral density and bone volume fraction (Sjogren et al., 2012; Yan and Charles, 2017). Modifications to the gut microbiota have also been shown to reduce bone loss caused by oestrogen depletion (Britton et al., 2014; Li et al., 2016) or glucocorticoid treatment (Schepper et al., 2020), two of the most common contributors to osteoporosis (Marcus, 2013). Changes in the gut microbiome can also mediate the effects of osteoporosis therapies such as the use of PTH (Li et al., 2020; Yu et al., 2020).

The gut microbiota is believed to influence bone metabolism through three main mechanisms: regulation of nutrient absorption, regulation of the host immune system and translocation of microbial products across the gut endothelial barrier (Hernandez et al., 2016). Probiotic bacteria, such as Lactobacillus and Bifidobacterium species can enhance mineral absorption at the gut lining either directly or by modulating the metabolism 
of bile acids (Rodriguez et al., 2013). Additionally, intestinal bacteria produce vitamins that are used by the host, including vitamins B1, B3, B5, B7, B12 and $K$, which influence bone health (Hernandez et al., 2016). Gut bacteria can also regulate bone health by interacting with immune cells at the gut lining. Then, activated immune cells may release cytokines into the systemic circulation or may migrate to the bone and more directly influence the activity of bone forming osteoblasts and bone resorbing osteoclasts. Molecules produced by bacteria can also directly influence the host. Microbial products known as MAMPs can pass through the gut endothelial barrier and into the systemic circulation. Then, MAMPs can stimulate inflammatory processes throughout the body and may stimulate innate immune receptors on osteoclasts and osteoblasts in the bone, thereby influencing bone remodelling (Hernandez, 2017). Additionally, the gut microbiota also produces metabolites such as SCFAs.

\section{SCFAs have been implicated as a key link between the microbiome and bone}

Much of the understanding of how the gut microbiome interacts with bone is focused on osteoporosis, bone growth and remodelling, which have already been summarised in numerous excellent reviews (Hernandez, 2017; Pacifici, 2018; Yan et al., 2018). Other reviews have described the role of the microbiota in tissue repair and regeneration (Shavandi et al., 2020) as well as the gut microbiome-cartilage axis as new paradigm for osteoarthritis therapy (Berthelot et al., 2019). One recently published study highlighted the potential of probiotic Bifidobacterium adolescentis (B. adolescentis) ATCC 15703 in promoting fracture healing in mice. Orally administrated probiotic $B$. adolescentis ATCC 15703 increases callus cartilage remodelling in male C57BL/6J mice, which likely is a consequence of increased gene expression of gut tight junction proteins - including occludin, Jam3, Tjp1, Claudin-3, Claudin-4 and Claudin-15 - as well as lower systemic levels of inflammatory IL-6 and IL-16 cytokines (Roberts et al., 2020). Similarly, orally supplemented Akkermansia muciniphila (A. muciniphila) was shown to decrease inflammatory IL-1 $\beta$, IL- 6 and TNF $\alpha$ in the femur fracture area in mice two weeks post-fracture (Liu et al., 2020). The anti-inflammatory effect of $A$. muciniphila likely leads to increased angiogenesis in callus by promoting type $H$ vessel formation, which consequently leads to higher bone volume/total volume of fracture callus in these mice. These studies emphasise the potential of the gut microbiota to positively impact bone healing. In the present review, the known effects of key mediators of the gut microbiota, namely SCFAs, on bone healing are described, with a focus on the individual cells involved in fracture healing such as osteoblasts, osteoclasts, fibroblasts and chondrocytes. Finally, the use of SCFAs in biomedical engineering approaches to support bone health secondary to bone loss is described.

\section{The importance of microbial-derived SCFAs}

Generation and origin of SCFAs

SCFAs are a major class of metabolites produced by the gut microbiota following fermentation of dietary fibres and are readily produced upon consumption of whole grain products, vegetables and fruits (Fig. $1)$. Those non-digestible fibres escape digestion and absorption in the small intestine and are later fermented in the caecum and large intestine by anaerobic caecal and colonic microbiota (den Besten et al., 2013). The microbially-derived SCFAs formate, acetate, propionate, butyrate and valerate (also termed pentanoate) are commonly found within the gut and are composed of either one (formate), two (acetate), three (propionate), four (butyrate) or five (valerate) carbon atoms (Morrison and Preston, 2016). Their concentrations vary depending on diet and different colon sites, but generally range between $10 \mathrm{mmol} / \mathrm{L}$ and $100 \mathrm{mmol} / \mathrm{L}$ in the colon lumen (Koh et al., 2016).

Butyrate is produced by bacteria belonging to the phylum Firmicutes and the order Clostridiales and part of either the Clostridiaceae, Eubacteriaceae, Lachnospiraceae or Ruminococcaceae families, including Faecalibacterium prausnitzii, Eubacterium rectale, Eubacterium hallii, Roseburia species and Ruminococcus bromii (Fu et al., 2019; Louis et al., 2010). Butyrate, the most investigated SCFA to date, is synthesised from two molecules of acetyl-CoA, producing acetoacetylCoA, which is further converted to butyryl-CoA via beta-hydroxybutyric-CoA and crotonyl-coA (Koh et al., 2016). Acetate, the most abundant SCFA in the gut, is produced by most enteric bacteria, such as Bacteroides, Bifidobacterium and Prevotella species (Koh et al., 2016) and is generated from pyruvate via acetylCoA and the Wood-Ljungdahl pathway (Ragsdale and Pierce, 2008). Propionate is produced by many different gut microbes, including Veillonella species, Coprococcus catus and Salmonella species (Koh et al., 2016). Propionate-producing microbes use either the propanediol pathway from deoxyhexose sugars, such as fucose and rhamnose, the succinate pathway by converting succinate to methylmalonyl-CoA or the acrylate pathway, in which lactate is reduced to propionate (Koh et al., 2016). Valerate, a rather poorly studied metabolite, can be produced by Clostridium cluster I and its fermentation involves propionate coupling with ethanol (Oliphant and Allen-Vercoe, 2019). Valproate is a branched SCFA generated from valerate. Valproate is not naturally generated upon microbial fermentation, but rather is synthetically produced. Valproate is extensively used clinically for the treatment of epilepsy and seizures but has also been investigated as an adjuvant agent for many other pathologies, such as cancer or HIV therapy, based on its action as an HDAC inhibitor (Ghodke-Puranik et al., 2013).

\section{Receptors and transporters of SCFAs}

SCFAs have a direct effect on host cells at the gutendothelial barrier and are transported through these 
cells and subsequently throughout the body, thereby affecting distant tissues. Several GPR (also known as FFAR), bind SCFAs, namely GPR41 (FFAR3), GPR43 (FFAR2) and GPR109a. GPR41 and GPR43 can be activated by acetate, propionate, butyrate or valerate, whereas GPR109a is mainly activated by butyrate (Sun et al., 2017b). These membrane-bound receptors are expressed on a variety of immune cell types, including monocytes/macrophages, but also on gut epithelial cells, adipocytes, enteroendocrine cells and pancreatic islets (Husted et al., 2017; Sun et al., 2017b). GPR41 and GPR43 show $52 \%$ similarity and $43 \%$ identity, which explains why they are activated by similar ligands; however, GPR41 has different specificity for carbon chain length, resulting in a preference for valerate as an agonist (Brown et al., 2003). Binding of SCFAs to GPRs leads to an intracellular release of $\mathrm{Ca}^{2+}$ and to activation of different downstream signalling pathways, such ERK/MAPK, JNK, p38 or Akt/PI3K kinase cascades, which not only regulate cell differentiation, proliferation, migration and survival, but also cytokine and chemokine production (Melhem et al., 2019).

SCFAs, in particular butyrate, are a primary energy substrate for intestinal epithelial cells and directly affect growth and differentiation of these cells (Parada Venegas et al., 2019). Nonetheless, a certain quantity of SCFAs reach the bloodstream by different transfer systems: carrier-mediated transporters, such as SMCT1/Slc5a8 ( $\mathrm{Na}^{+}$-driven) and MCT1/Slc16a1 $\left(\mathrm{H}^{+}\right.$-driven $)$, which are located on the colonic epithelium, support the transport of SCFAs from the gut lumen into the bloodstream leading to the portal vein and liver (Sun et al., 2017b). Slc5a8, a high-affinity transporter for butyrate, protects against colitis and colon cancer by regulating the development of regulatory $\mathrm{T}$ (Treg) cells and the expression of IDO1 and Aldh1A2 in DCs under conditions of low-fibre intake (Gurav et al., 2015). In addition to receptor and transporter-mediated transfer, SCFAs can also reach the bloodstream by free passive diffusion. Once SCFAs reach the systemic circulation, they can affect the metabolism and function of peripheral tissues such as adipose tissue, skeletal muscle, bone and liver via GPRs (Sun et al., 2017b; Zaiss et al., 2019; Zhou and Fan, 2019) (Fig. 1).

\section{SCFAs as HDAC inhibitors}

SCFAs, mainly butyrate but also propionate, are known to inhibit HDACs and are therefore involved in epigenetic regulation of gene expression. HDACs remove acetyl groups from histone tails, which leads to a repressive chromatin structure, therefore dampening gene transcription. Thus, HDAC inhibitors promote histone acetylation and are mainly known to alter the cell cycle, which is of importance in terms of their capacity to inhibit proliferation of cancerous cells.

\section{The role of SCFAs in immunity}

Many studies have reported that the immunomodulatory activities of SCFAs are not restricted to the intestines, where they induce antiinflammatory responses involving Treg cells and IL-10 production (Luu and Visekruna, 2019), but also affect immune homeostasis at other distant sites such as the urinary, respiratory and nervous systems (Ratajczak et al., 2019).

In addition to the capacity of SCFAs to shape the adaptive immune response, notably Treg cell induction, they can also impact cells from the innate immune response, such as macrophages. In particular, exposure of peripheral blood mononuclear cells, including macrophages, to SCFAs or HDAC inhibitors, such as TSA, inhibits pro-inflammatory TNF $\alpha$ production (Usami et al., 2008). In addition, butyrate boosts antimicrobial activity of macrophages, including inhibition of HDAC3, inducing differentiation of macrophages with enhanced bactericidal functions (Lobel and Garrett, 2019; Schulthess et al., 2019).

The broad effects of SCFAs on immune cell function have already been reviewed extensively (Correa-Oliveira et al., 2016; Li et al., 2018; Ratajczak et al., 2019). As highlighted above, the anti-inflammatory capacities of SCFAs are a key aspect of their biological importance. Several in vitro studies have shown that butyrate induces anti-inflammatory IL-10 and TGF- $\beta$ production and inhibits pro-inflammatory cytokine/ chemokine production such as IFN $\gamma, \mathrm{TNF} \alpha$, IL-1 $\beta$, IL-6 and IL- 8 by inhibiting activation of the transcription factor NFKB (Liu et al., 2018). The induction of Treg cell differentiation by butyrate has been shown in the colon and spleen of mice (Furusawa et al., 2013; Hui et al., 2019). Butyrate can also induce apoptosis in macrophages (Ramos et al., 2002), neutrophils (Aoyama et al., 2010) and lymphocytes (Kurita-Ochiai et al., 2001), therefore potentially preventing excessive immune cell activation. Also, SCFAs can have proinflammatory effects by initiating chemotaxis in leukocytes, notably in neutrophils (Vinolo et al., 2011). In contrast, in an atherosclerotic apoE knockout mouse model, butyrate reduces CCL2/MCP-1, VCAM-1 and MMP-2 production, preventing the progression of atherosclerosis (Aguilar et al., 2014). Thus, depending on the concentration and frequency of SCFA supplementation, SCFAs may differentially affect immune cell populations.

\section{Bone fractures: clinical problem and the biological processes of fracture healing}

Bone is a highly dynamic tissue capable of healing without residual scar. However, for reasons not fully understood, a small number of long-bone fractures (5-10 \%) suffer from healing complications, such as delayed healing and potential to progress to nonunion (Haas, 2000; Hernandez et al., 2012; Tzioupis and Giannoudis, 2007). Several co-morbidities, such 
as diabetes and smoking, are established risk factors for healing complications (Zura et al., 2016), which are likely attributable to diminished revascularisation following fracture. However, there remains a small subset of apparently healthy patients also afflicted by delayed bone healing, indicating that there is an urgent need to fully understand the mechanisms underlying this phenomenon.

Following fracture, bone heals predominantly via two distinct mechanisms: intramembranous or primary bone healing, which typically occurs following close abutment of the bone fragments and a high degree of mechanical stability (such as stress fractures); endochondral or secondary bone healing, which involves the formation of a cartilaginous fracture callus that serves as a template for subsequent replacement with bone tissue (for reviews see Einhorn and Gerstenfeld, 2015; Morgan et al., 2014). Interestingly, a recent transcriptomic analysis comparing intramembranous bone healing with endochondral bone healing has demonstrated pronounced differences in the early response of bone tissue to injury (Coates et al., 2019). Specifically, endochondral fracture healing triggers a markedly early inflammatory response, indicating that endochondral fracture healing involves a complex interplay of signals derived from both bone resident cells but also other cells, including immune cells and MSCs (Kovach et al., 2015). This is consistent with numerous other studies that have highlighted the necessity of an initial pro-inflammatory burst to trigger the healing response and confirm that effective resolution of this pro-inflammatory environment is necessary for later stages of cartilaginous callus remodelling into bone tissue (Hoff et al., 2016; Loffler et al., 2019; Muire et al., 2020; Schmidt-Bleek et al., 2015). Indeed, several recent studies have highlighted that failure to effectively resolve this pro-

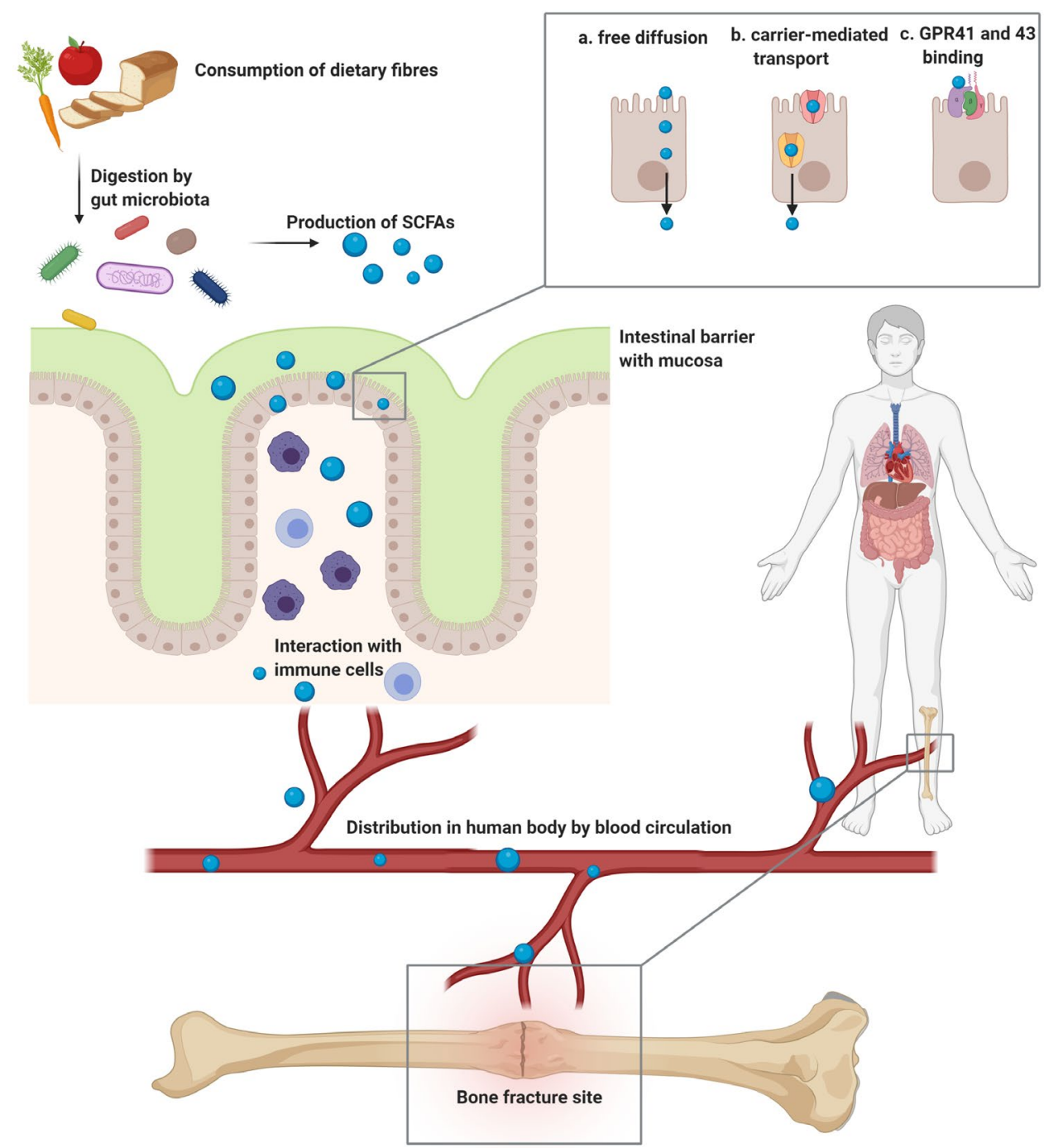

Fig. 1. Production of SCFAs and systemic distribution to the bone fracture site. SCFAs are generated by the gut microbiota upon fermentation of dietary fibres. SCFAs can cross the intestinal barrier by either (a) free diffusion, (b) carrier-mediated transporters or (c) binding to GPR41 and 43. In the intestinal tissue, they interact with cells from the immune system, such as T cells and macrophages. Further, SCFAs are distributed in the human body by the bloodstream and reach different organs and tissue sites, including bone. At the bone fracture site, SCFAs influence the different cell types and biological processes involved in fracture healing. Figure created using BioRender.com. 
inflammatory environment is associated with delayed long-bone healing in patients (Reinke et al., 2013; Sun et al., 2017a; Yang et al., 2015). This raises the exciting possibility that modulation of systemic inflammatory mediators through the microbiome could provide a means for improving fracture healing outcomes in high-risk patient populations.

\section{SCFAs affect bone healing}

The effects of SCFAs on the host can lead to profound effects on fracture healing. SCFAs may alter fracture healing through their indirect effects on systemic immunity. Additionally, systemically distributed
SCFAs can attain biologically relevant concentrations in bone marrow where they can have direct effects on cells involved in the fracture-healing process (Fig. 2).

\section{Inflammatory response and immune cell recruitment} Numerous studies have been performed to investigate the impact of SCFAs on the differentiation and function of macrophages. Macrophages play a central role in the process of bone fracture healing since they are not only present during the initial inflammatory state immediately after the bone fracture, but they also reside at the injury site for the entire healing phase. Pro-inflammatory M1 macrophages are

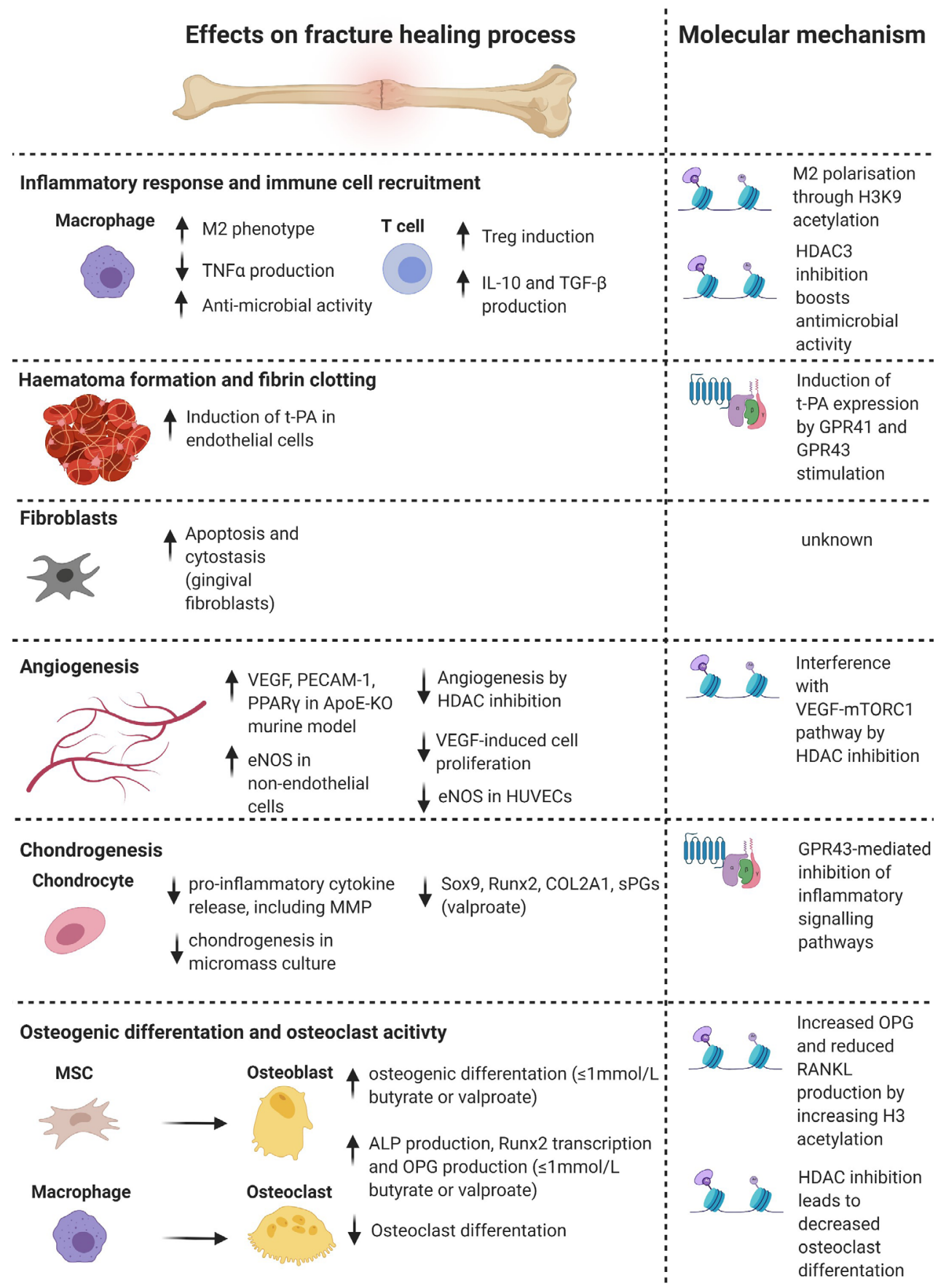

Fig. 2. Effects and molecular mechanisms of SCFAs on cell types and biological processes involved in bone fracture healing. SCFAs influence the individual stages of fracture healing and the different cell types involved. Histone modifications, mainly mediated by HDAC inhibition, and GPR-signalling are the main molecular mechanisms mediating the effects of SCFAs. M2 = macrophage-phenotype 2; ApoE-KO=Apo-E knock-out. Figure created using BioRender.com. 
dominant during the initial healing step, but tissue reparative M2 macrophages are more prevalent during the endochondral ossification phase (Schlundt et al., 2018). A shift from the M1 to M2 macrophage phenotype is crucial to support proper bone healing.

Butyrate has been shown in vitro and in vivo to facilitate the polarisation of macrophages to the M2 phenotype, by activating the STAT6-mediated transcription through $\mathrm{H} 3 \mathrm{~K} 9$ acetylation (Ji et al., 2016). Notably, monocyte/macrophage-lineage cells are the precursors for bone resorbing osteoclasts. Several studies have shown the inhibitory effect of SCFAs on osteoclast maturation and function, which will be discussed later.

\section{Haematoma formation and fibrin clotting}

Haematoma formation and fibrin clotting are crucial processes in the first stage of fracture healing. Butyrate was shown to influence fibrin degradation by stimulating t-PA synthesis in human endothelial cells in vitro (Kooistra et al., 1987). Interestingly, acetate, propionate, butyrate and valerate also induced t-PA expression in primary human bronchial epithelial cells by stimulating GPR41 and GPR43 (Imoto et al., 2018). The availability of t-PA plays an important role in the extrinsic fibrinolytic route by converting plasminogen into the active plasmin, which degrades fibrin. In addition to its fibrinolytic function, plasmin is also involved in all tissue repair processes including bone fracture repair, which involve various mechanisms such as stem cell homing (Mignemi et al., 2017). Haematoma formation and fibrin clotting were also shown to be inhibited by valproate in the context of intra-abdominal lesions. In a study administering a single intraperitoneal dose of $50 \mathrm{mg} / \mathrm{kg}$ valproate after the creation of peritoneal ischemic buttons in a rat model, adhesions as well as levels of fibrinogen and VEGF were reduced by $50 \%$, $56 \%$, and $25 \%$, respectively, in harvested button tissue, relative to control. This suggests that SCFAs and valproate potentially influence bone healing by modifying the pathways involved in fibrin degradation and regulating the availability of VEGF.

\section{Fibroblasts}

Fibroblasts migrate to the fracture region and deposit initial collagen and proteoglycans found in granulated tissue. Several studies have shown that butyrate and propionate have a negative impact on the survival and proliferation of gingival fibroblasts in vitro (Jeng et al., 1999; Kurita-Ochiai et al., 2008; Shirasugi et al., 2017; Takigawa et al., 2008). Butyrate and propionate have been shown to induce apoptosis and cytostasis of healthy and inflamed gingival fibroblasts in vitro in both primary human cells and in cell lines. These effects have been observed at concentrations ranging between 0.2 and $16 \mathrm{mmol} / \mathrm{L}$ across studies, although Kurita-Ochiai et al. (2008) observed this effect in inflamed primary gingival fibroblasts but not in healthy primary gingival fibroblasts. Butyrate concentrations of $1 \mathrm{mmol} / \mathrm{L}, 4 \mathrm{mmol} / \mathrm{L}$ and $16 \mathrm{mmol} / \mathrm{L}$ inhibit pro-inflammatory IL-6 and pro-fibrotic factor expression of human dermal fibroblasts (Maeshige et al., 2019). In contrast, Karna et al. (2009) showed that $4 \mathrm{mmol} / \mathrm{L}$ sodium butyrate, the sodium salt form of butyrate, stimulates collagen biosynthesis in cultured human skin fibroblasts, which is accompanied by increased expression of IGF-1 receptor. Based on these findings, it may be that lower concentrations $(<0.2 \mathrm{mmol} / \mathrm{L})$ of butyrate and propionate may support fibroblast survival, proliferation and migration, since cells modulate their activity depending on the applied SCFA concentration and the timing of SCFA application.

\section{Angiogenesis}

Following fibroblast infiltration and ECM deposition, angiogenesis begins to form vasculature to supply new tissue with oxygen and nutrients. Butyrate has both pro- and anti-angiogenic effects. In studies using an apoE knockout mouse model, an experimental model used to study obesity because of its high basal levels of oxidative stress, sodium butyrate was found to upregulate VEGF, PECAM- 1 and PPAR $\gamma$, which are relevant markers and factors of endothelial cells and neovascularisation in adipose tissue (Aguilar et al., 2018; Kotlinowski and Jozkowicz, 2016). The impact of sodium butyrate on angiogenesis was particularly investigated due to its potential as an anti-neoplastic therapeutic. Sodium butyrate inhibits VEGF-induced cellular proliferation, transmigration and tube formation of human intestinal microvascular endothelial cells in vitro by a mechanism involving inhibition of COX-2 expression and prostaglandin production (Ogawa et al., 2003). In addition, butyrate suppresses eNOS protein levels in a time- and concentration-dependent manner in HUVECs (Rossig et al., 2002) as well as in the tubular and glomerular regions of murine kidney (Khan and Jena, 2014). In contrast, eNOS expression is increased in non-endothelial cells following TSA and sodium butyrate treatment (Gan et al., 2005). Deroanne et al. (2002) showed that the HDAC inhibitor TSA has anti-angiogenic effects by preventing the formation of a capillary-like network of HUVECs, indicating that HDAC inhibition is a crucial mechanism in the prevention of angiogenesis. In addition to butyrate and TSA, valproate has anti-angiogenic effects. Iizuka et al. (2018), using a murine ischemic retinal neovascularisation model, found valproate to interfere with the VEGF-mTORC1 pathway via HDAC inhibition. VEGF relies on mTOR-dependent pathways to induce endothelial cells proliferation and initiate angiogenesis (Iizuka et al., 2018). A recent review analysing the role of PPAR $\gamma$ in angiogenesis cited studies that suggested both pro- and antiangiogenic properties (Kotlinowski and Jozkowicz, 2016). However, the authors concluded that VEGF expression is independent of PPAR $\gamma$, suggesting that the differing effects of butyrate and valproate are likely not due to an upregulation of PPAR $\gamma$ in the apoE mouse model. One possible explanation 
for the reported differences could be that the serum elimination half-life of valproate $(16 \mathrm{~h})$ is much longer than that of butyrate ( $2.5 \mathrm{~h}$ ) (Conley et al., 1998; Ibarra et al., 2013).

\section{Chondrogenesis}

The chondrogenic differentiation of BM-MSCs and the subsequent formation of a callus is a crucial step for initialising successful endochondral fracture healing. A study analysing the effects of sodium butyrate on the differentiation of embryonic limb bud cells found that concentrations of butyrate ranging between 0.03 and $1 \mathrm{mmol} / \mathrm{L}$ inhibit chondrogenesis in micromass cultures (Garrison et al., 1989). Valproate downregulates Sox 9 and Runx2, which are important regulators of chondrogenesis and osteogenesis in mice (Paradis and Hales, 2013), and decreases chondrogenic markers such as type II collagen and sulphated proteoglycan production in human chondrocytes (Aulthouse and Hitt, 1994). Butyrate inhibits the most potent inflammatory signalling pathways, including a reduction in pro-inflammatory cytokine production, in murine chondrocytes via a GPR43-mediated pathway (Pirozzi et al., 2018). Additionally, butyrate limits the production of catabolic MMPs and reduces inflammation-induced type II collagen degradation in explant culture (Young et al., 2005). Interestingly, the mechanism of butyrate's anti-inflammatory effects is independent of NF-kB DNA binding activity in human chondrocytes (Chabane et al., 2008), despite the important role of NF- $\mathrm{kB}$ as a mediator of the production of the potent pro-inflammatory cytokine IL- $1 \beta$ in chondrocytes.

\section{Osteogenic differentiation and osteoclast activity}

Following angiogenesis and the proliferative phase, which forms fibrous tissue in the callus, MSCs differentiate into osteoblasts or chondrocytes to begin the bone formation phase of fracture healing. Recent literature has suggested that physiological concentrations of butyrate can enhance the osteogenic phenotype of osteoblasts. Several studies have found that butyrate, at concentrations ranging between $500 \mathrm{nmol} / \mathrm{L}$ and $1 \mathrm{mmol} / \mathrm{L}$, increases ALP production in murine calvarial organ cultures, Runx2 transcription in MC3T3-E1 cells (Schroeder and Westendorf, 2005) and calcium content and OPG expression of mineralised nodules in human osteoblasts (Katono et al., 2008). OPG is the decoy receptor for the crucial osteoclast differentiation factor RANKL, which indirectly leads to bone formation by reducing osteoclast activity (Katono et al., 2008). Similar studies have found sodium butyrate to only have osteogenic effects at concentrations below $1 \mathrm{mmol} / \mathrm{L}$ after exposure for no longer than $3 \mathrm{~d}$ in human amniotic-membrane-derived MSCs, after which time, and at higher concentrations, the stimulatory effect of butyrate on osteogenesis is abolished (Fan et al., 2018). Valproate also enhances the viability of primary osteoblasts at low concentrations in vitro (Schroeder and Westendorf, 2005). At higher, super-physiological concentrations, the effect of SCFAs on osteoblast phenotype and survival is markedly different, resulting in cytotoxicity and enhanced RANKL production. Chang et al. (2018) found butyrate at $2-16 \mathrm{mmol} / \mathrm{L}$ to stimulate RANKL production and reduce OPG expression in MG-63 osteoblastic cells $24 \mathrm{~h}$ after exposure. However, this study also observed increased expression of OPG and reduced RANKL production after $3 \mathrm{~d}$ of exposure to lower concentrations of butyrate (1-8 $\mathrm{mmol} / \mathrm{L})$ by increasing histone $\mathrm{H} 3$ acetylation.

Osteoclasts play an important role throughout the entire duration of fracture healing, helping to remodel bone in the periosteal callus and the endosteal space. Interestingly, Lucas et al. (2018) found butyrate and propionate to inhibit osteoclastogenesis and bone resorption in vitro and in vivo, with bone formation and osteoblasts unaffected, which protected ovariectomised mice against bone loss. Different studies have shown that SCFAs, in particular butyrate, can inhibit osteoclastogenesis. In the presence of $0.5 \mathrm{mmol} / \mathrm{L}$ sodium butyrate, osteoclast differentiation in rat bone marrow cultures was markedly reduced, showing a $98 \%$ reduction in TRAP-positive multinucleated osteoclast-like cells. However, sodium butyrate did not affect the differentiation of macrophages in bone marrow cultures, since NSE, an enzyme marker for macrophages, and the macrophage surface expression markers Mac-1 and F4/80, remained unchanged in the presence of sodium butyrate (Rahman et al., 2003). The remarkable effects of sodium butyrate on osteoblastic and osteoclastic cells were already described in the 1990s, where $0.5 \mathrm{mmol} / \mathrm{L}$ sodium butyrate increased ALP activity in differentiating osteoblasts. However, the timing of sodium butyrate addition is critical, since ALP activity is only increased if sodium butyrate is added to cells before they reached confluency. Besides the effect of enhancing osteoblast differentiation, treatment of bone marrow cells with sodium butyrate leads to reduction in TRAP-positive multinuclear cell formation. This reduction is due to a cytotoxic effect of sodium butyrate $(0.25-2.5 \mathrm{mmol} / \mathrm{L}$ ) (Iwami and Moriyama, 1993).

The fact that TSA, a pan-HDAC inhibitor, reduces osteoclast formation from bone marrow cells indicates that HDAC inhibition might be one of the key mechanisms for reducing osteoclast formation in the presence of butyrate (Rahman et al., 2003; Yi et al., 2007). Interestingly, valproate, another known HDAC inhibitor, increases osteogenic differentiation in a dose-dependent manner by increasing expression of osteogenic genes such as osterix, osteopontin, BMP-2 and Runx2 (Cho et al., 2005).

Besides their direct effect on osteoblast and osteoclast differentiation and activity mediated mainly by HDAC inhibition (Rahman et al., 2003; Yi et al., 2007), SCFAs additionally influence bone formation in a Treg-dependent manner. Butyrate produced upon probiotic Lactobacillus rhamnosus 
supplementation regulates bone mass through Treg cell-mediated production of the bone anabolic CD8 ${ }^{+}$ $\mathrm{T}$ cell Wnt10b ligand in mice (Tyagi et al., 2018). In addition, butyrate-mediated induction of Treg cells can prevent osteoclast formation by Treg secreted anti-osteoclastogenic cytokines, such as IL-10, and through a CTLA4/CD80/86 cell-cell contactdependant mechanism (Zaiss et al., 2019). However, Rag1 knock-out mice (lacking $\mathrm{T}$ and B cells) still shows increased bone densities following propionate and butyrate treatment, highlighting the strong direct osteoclast-suppressing effect of propionate and butyrate (Lucas et al., 2018).

Although individual studies have investigated the impact of different classes of SCFAs on survival, proliferation, differentiation and activation of the cell types involved in bone healing, confirmatory studies in bone fracture models remain to be performed and there is no clinical data from human cohorts, to the best of the authors' knowledge.

\section{The gut microbiota and osseointegration}

\section{Differences between osseointegration and fracture healing}

As reviewed above, fracture healing involves a cascade of events with both anabolic and catabolic stages. Most discussions on fracture healing focus on endochondral ossification within the fracture callus because the soft callus plays a dominant role in healing of a complete fracture. Intramembranous ossification also contributes to fracture healing and is the primary mechanism used by the body to achieve bony ingrowth to secure an orthopaedic implant. The phases of intramembranous ossification start with a blood clot followed by vascular invasion and subsequent migration of MSCs that differentiate directly into osteoblasts and form bone tissue (Ko and Sumner, 2020). There are two key differences between intramembranous ossification in osseointegration and endochondral ossification in fracture healing. Firstly, osseointegration does not involve the cartilage precursor observed in a soft callus. The absence of a cartilage precursor reduces the importance of the catabolic phase of fracture healing that removes and replaces the cartilage. Secondly, osseointegration occurs predominately within the marrow space and is, therefore, dominated by mesenchymal cell populations originating within the marrow space with relatively little contribution from stem cells originating within the periosteum (Ko and Sumner, 2020). The difference in stem cell source may greatly modify how the microbiome influences osseointegration (see below).

Potential role of the microbiome in osseointegration Although to the authors' knowledge there have not been any direct studies of the effects of the gut microbiome on osseointegration, the current understanding of the effects of the gut microbiome on bone cells suggests a potentially potent effect on osseointegration (Fig. 3). Modifications to the gut microbiome have been shown in animals to cause rapid changes in bone formation and resorption that could influence osseointegration. For example, the introduction of a gut microbiota into young (7-9 weeks old) germ-free mice causes increases in bone formation rate in both trabecular and cortical bone 4 weeks afterwards (Schepper et al., 2019; Sjogren et al., 2012; Yan et al., 2016). Removal of large components of the gut microbiota, using broadspectrum antibiotic cocktails for 1 month, leads to reductions in bone formation rate (Schepper et al., 2019; Yan et al., 2016). However, the effect of changes in the gut microbiome on bone formation in these mice models appears to be transient: 8 months after the introduction of gut microbes to a germ-free mouse, overall trabecular bone volume fraction and markers of bone resorption and formation are indistinguishable from similarly aged mice maintained under germ-free conditions (Yan et al., 2016). The transient nature of the bone remodelling response to abrupt alterations to the gut microbiota raises the possibility that modifications to the gut microbiome initiated around the time of surgery could have a beneficial (or perhaps even detrimental) effect on bone formation at the implant surface immediately after surgery - during the critical period when osseointegration is required for overall surgical success (Chong et al., 2010).

Although microbe-derived vitamins produced within the gut have been implicated as a potential regulator of bone matrix quality (Guss et al., 2019), the effects of the gut microbiome on bone remodelling have so far been associated with regulation of systemic hormones, including IGF-1 (Yan et al., 2016), and on the stimulation of $T$ cells at the gut lining that then migrate to the bone (Pacifici, 2018). IGF-1 has long been recognised as a regulator of bone remodelling and has direct and indirect effects on osteoclast and osteoblast activity throughout the body (Guntur and Rosen, 2013). Stimulation of T cells by the gut microbiota and SCFAs produced by the gut microbiota alter the function of Treg cells that migrate to the bone marrow (Zaiss et al., 2019). The presence of segmented filamentous bacteria in the gut microbiota is required for substantial loss of trabecular bone following oestrogen depletion or continuous PTH therapy by recruiting Th17 cells to the bone marrow. However, microbe-derived butyrate is required to increase bone formation in regions of trabecular bone following intermittent PTH treatment (Li et al., 2020; Yu et al., 2020). The effect of the gut microbiome on the response to intermittent PTH is believed to be derived from Treg populations in the bone marrow, a finding consistent with the observation that the constituents of the microbiome modulate the effects of PTH predominantly on trabecular bone and not on cortical bone. The focused effect of the microbiome on PTH-induced bone formation in cancellous bone suggests the possibility that microbiome-induced 
changes in bone marrow resident immune cells could influence bone formation at the surface of implants secured in regions of cancellous bone, including the stems of implants used in total joint arthroplasty.

\section{SCFAs in tissue engineering constructs}

The potential beneficial effects of SCFAs on cells involved in fracture healing have led to their use in tissue engineering and regenerative medicine applications. Derivatives of butyrate and valerate have been used in a variety of tissue engineering and bone regeneration applications because of their ability to reduce inflammation and increase bone tissue production (Coburn et al., 2013; Jung et al., 2010). Small molecules, such as butyrate and valerate, can be readily synthesised and incorporated in tissueengineering constructs. A SCFA-hexosamine hybrid molecule, namely 3,4,6-O-Bu3GlcNAc, could decrease the expression of the pro-inflammatory $\mathrm{NF} \kappa \mathrm{B}$ target genes in vitro, which are relevant for osteoarthritis (Coburn et al., 2013). Additionally, even more relevant in the context of fracture healing, 3,4,6-O-Bu3GlcNAc could stimulate production of both sulphated GAG and total collagen, reflecting ECM accumulation, by IL-1 $\beta$-stimulated chondrocytes in vitro using a threedimensional hydrogel culturing system (Coburn et al., 2013). The incorporation of butyrate into $\alpha$ calcium sulphate suppresses osteoclast phenotypic expression in vitro and enhances osteoblastic differentiation (Jung et al., 2010). This finding was validated in a rat calvarial critical-sized bone defect model, where the butyrate-loaded $\alpha$ calcium sulphate leads to new bone formation, by delaying resorption and enhancing osteoblast differentiation. The combination of butyrate with DMOG in $\alpha$ calcium sulphate leads to a synergistic enhancement in bone regeneration, again in a critical-sized rat calvarial bone defect model, by increasing the pro-angiogenic response and osteoblast differentiation (Woo et al., 2015). Of particular note, PHAs are a class of polyesters produced by microorganisms, which are stored intracellularly as an energy source. The most widely used and first PHA to be discovered was $\mathrm{PBH}$, although others, such as hydroxyvalerate, have been used in drug delivery applications (Tokiwa and Calabia, 2004). Because of its promising mechanical properties, biocompatibility and biodegradability, $\mathrm{PBH}$ has been used experimentally as a potential drug delivery and bone defect scaffold. One of the primary degradation products of $\mathrm{PBH}$ is $\beta$-hydroxybutyrate, an endogenous SCFA with chemical and functional similarity to butyrate (Chriett et al., 2019; Karahaliloglu et al., 2015). After being released by the colon and travelling through the bloodstream, SCFAs are

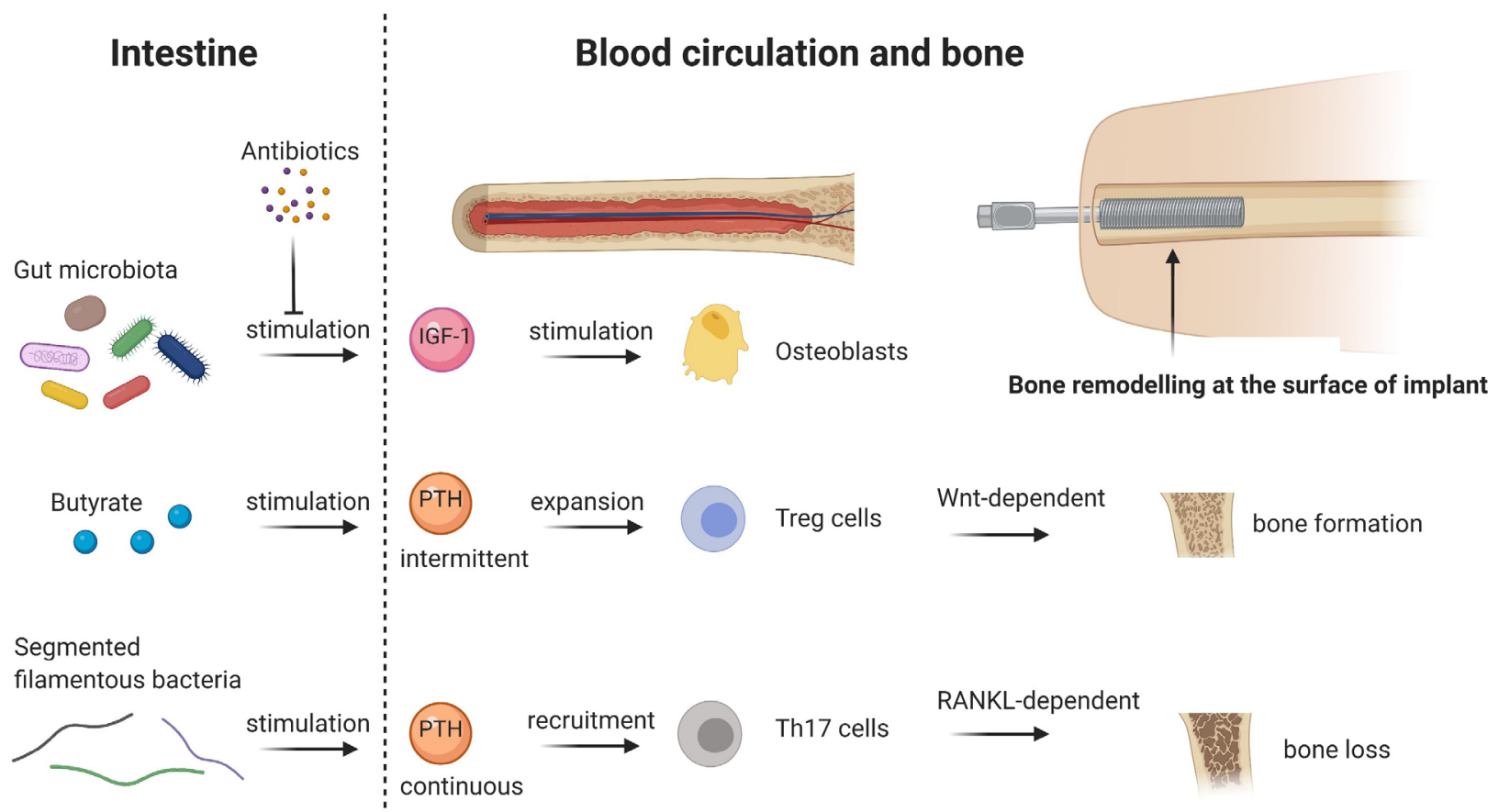

Fig. 3. Potential influence of the gut microbiota and their associated SCFAs on osseointegration. The presence of the gut microbiota increases IGF-1 hormone levels in serum, which further stimulate osteoblasts and bone formation, respectively. In contrast, eradication of the gut microbiota by antibiotics decreases IGF-1 in serum and, therefore, inhibits bone formation. SCFAs, namely butyrate, stimulate intermittent, physiological PTH release, which expands Treg cells in the bone marrow and further enhances bone formation in a Wnt-dependent way. However, the presence of segmented filamentous bacteria stimulates continuous PTH release, as it is the case in hyperthyroidism. This leads to Th17 recruitment in the bone marrow and causes RANKL-dependant bone loss. Bone remodelling, in particular bone formation, at the surface of an implant is crucial for proper osseointegration and the gut microbiota could be a potent regulator in this process. Wnt = wingless-related integration site. Figure created using BioRender.com. 
commonly metabolised by the liver to produce $\beta$-hydroxybutyrate during fatty acid $\beta$-oxidation (Selkrig et al., 2014). $\beta$-hydroxybutyrate is also often produced during ketogenesis in response to low blood glucose in situations of starvation or excessive exercise. When used as a graft or scaffold, PHB has osteogenic and osteoplastic effects. Shumilova et al. (2017), using a cranial defect model in rats, showed that scaffolds composed of PHB without cells enhance regeneration in the defect, resulting in only $10 \%$ of the defect left behind after $120 \mathrm{~d}$, according to CT image analysis. PHB seeded with osteoblasts completely healed the defect, while a negative control and a positive control using commercial material resulted in 20-24\% of the defect remaining unfilled (Shumilova et al., 2017). Gredes et al. (2015) using a rat cranial defect model drew similar conclusions, with bone regeneration occurring in all defects treated with PHB implants. This study also showed enhanced angiogenesis in groups treated with PHB. Bernd et al. (2009) using a dura-mater-defect model in minipigs also found PHB to be a biocompatible and biodegradable material suitable for healing the defect. In addition, using an osteotomy model in rats, PHB implants, as well as PHB with hydroxyapatite, induce complete healing of the osteotomy after $90 \mathrm{~d}$ compared to controls with incomplete healing and less new bone formation (Shishatskaya et al., 2014). Interestingly, this study also used an osteomyelitis model in rabbits and found PHB to have anti-bacterial effects, resulting in faster and more complete healing at the site of the inoculated defect compared to controls. The biodegradation of PHB is slow and closely aligns with the formation of new bone. Because of the slow degradation of $\mathrm{PHB}$, there is likely a steady, yet small (mmol/L) concentration of $\beta$-hydroxybutyrate in the region of the implant at all times during regeneration.

\section{Conclusions and future directions}

The gut microbiome has emerged as a major modifiable component in the pathophysiology of multiple human disorders and is increasingly being viewed as an important factor for orthopaedic-related conditions. Recent studies suggest that microbederived SCFAs provide an important link between the gut microbiome and bone. The mechanisms described in the present review suggest a potentially strong effect of the microbiome and SCFAs on fracture healing, regenerative medicine devices used to promote fracture healing and the integration of traditional orthopaedic implants. Although early evidence is promising, particularly with regards to the strong immunomodulatory effects of SCFAs and their effects on osteoclasts and osteogenic differentiation, to date, no study has definitively shown a link between SCFAs and bone fracture healing. Recent evidence regarding probiotic supplementation on fracture healing is promising. Nevertheless, further research is required to utilise the microbiome and its metabolites in a manner beneficial for fracture healing. The specific mechanisms through which the gut microbiome influences fracture healing are yet to be fully determined and the role of SCFAs in fracture healing and osseointegration requires further studies. In addition to the contribution of naturally distributed SCFAs to fracture healing, it is likely that SCFA-derivatives linked or incorporated within different tissue-engineered constructs will be exploited to enhance osteogenic differentiation and, therefore, support bone defect healing in the coming decades.

\section{References}

Aguilar EC, da Silva JF, Navia-Pelaez JM, Leonel AJ, Lopes LG, Menezes-Garcia Z, Ferreira AVM, Capettini L, Teixeira LG, Lemos VS, Alvarez-Leite JI (2018) Sodium butyrate modulates adipocyte expansion, adipogenesis, and insulin receptor signaling by upregulation of PPAR-gamma in obese Apo E knockout mice. Nutrition 47: 75-82.

Aguilar EC, Leonel AJ, Teixeira LG, Silva AR, Silva JF, Pelaez JM, Capettini LS, Lemos VS, Santos RA, Alvarez-Leite JI (2014) Butyrate impairs atherogenesis by reducing plaque inflammation and vulnerability and decreasing NFkB activation. Nutr Metab Cardiovasc Dis 24: 606-613.

Aoyama M, Kotani J, Usami M (2010) Butyrate and propionate induced activated or non-activated neutrophil apoptosis via HDAC inhibitor activity but without activating GPR-41/GPR-43 pathways. Nutrition 26: 653-661.

Aulthouse AL, Hitt DC (1994) The teratogenic effects of valproic acid in human chondrogenesis in vitro. Teratology 49: 208-217.

Baquero F, Nombela C (2012) The microbiome as a human organ. Clin Microbiol Infect 18 Suppl 4: 2-4.

Bernd HE, Kunze C, Freier T, Sternberg K, Kramer S, Behrend D, Prall F, Donat M, Kramp B (2009) Poly(3-hydroxybutyrate) (PHB) patches for covering anterior skull base defects - an animal study with minipigs. Acta Otolaryngol 129: 1010-1017.

Berthelot JM, Sellam J, Maugars Y, Berenbaum F (2019) Cartilage-gut-microbiome axis: a new paradigm for novel therapeutic opportunities in osteoarthritis. RMD Open 5: e001037. DOI: 10.1136/ rmdopen-2019-001037.

Britton RA, Irwin R, Quach D, Schaefer L, Zhang J, Lee T, Parameswaran N, McCabe LR (2014) Probiotic $L$. reuteri treatment prevents bone loss in a menopausal ovariectomized mouse model. J Cell Physiol 229: 1822-1830.

Brown AJ, Goldsworthy SM, Barnes AA, Eilert MM, Tcheang L, Daniels D, Muir AI, Wigglesworth MJ, Kinghorn I, Fraser NJ, Pike NB, Strum JC, Steplewski KM, Murdock PR, Holder JC, Marshall FH, Szekeres PG, Wilson S, Ignar DM, Foord SM, 
Wise A, Dowell SJ (2003) The orphan G proteincoupled receptors GPR41 and GPR43 are activated by propionate and other short chain carboxylic acids. J Biol Chem 278: 11312-11319.

Chabane N, Zayed N, Afif H, Mfuna-Endam L, Benderdour M, Boileau C, Martel-Pelletier J, Pelletier JP, Duval N, Fahmi H (2008) Histone deacetylase inhibitors suppress interleukin-1beta-induced nitric oxide and prostaglandin E2 production in human chondrocytes. Osteoarthritis Cartilage 16: 1267-1274.

Chang MC, Chen YJ, Lian YC, Chang BE, Huang CC, Huang WL, Pan YH, Jeng JH (2018) Butyrate stimulates histone $\mathrm{H} 3$ acetylation, 8-isoprostane production, RANKL expression, and regulated osteoprotegerin expression/secretion in MG-63 osteoblastic cells. Int J Mol Sci 19: 4071. DOI: 10.3390/ ijms19124071.

Cho HH, Park HT, Kim YJ, Bae YC, Suh KT, Jung JS (2005) Induction of osteogenic differentiation of human mesenchymal stem cells by histone deacetylase inhibitors. J Cell Biochem 96: 533-542.

Chong DY, Hansen UN, Amis AA (2010) Analysis of bone-prosthesis interface micromotion for cementless tibial prosthesis fixation and the influence of loading conditions. J Biomech 43: 1074-1080.

Chriett S, Dabek A, Wojtala M, Vidal H, Balcerczyk A, Pirola L (2019) Prominent action of butyrate over $\beta$-hydroxybutyrate as histone deacetylase inhibitor, transcriptional modulator and anti-inflammatory molecule. Sci Rep 9: 742. DOI: 10.1038/s41598-01836941-9.

Coates BA, McKenzie JA, Buettmann EG, Liu X, Gontarz PM, Zhang B, Silva MJ (2019) Transcriptional profiling of intramembranous and endochondral ossification after fracture in mice. Bone 127: 577-591.

Coburn JM, Wo L, Bernstein N, Bhattacharya R, Aich U, Bingham CO, 3rd, Yarema KJ, Elisseeff JH (2013) Short-chain fatty acid-modified hexosamine for tissue-engineering osteoarthritic cartilage. Tissue Eng Part A 19: 2035-2044.

Conley BA, Egorin MJ, Tait N, Rosen DM, Sausville EA, Dover G, Fram RJ, Van Echo DA (1998) Phase I study of the orally administered butyrate prodrug, tributyrin, in patients with solid tumors. Clin Cancer Res 4: 629-634.

Correa-Oliveira R, Fachi JL, Vieira A, Sato FT, Vinolo MA (2016) Regulation of immune cell function by short-chain fatty acids. Clin Transl Immunology 5: e73. DOI: 10.1038/cti.2016.17.

den Besten G, van Eunen K, Groen AK, Venema K, Reijngoud DJ, Bakker BM (2013) The role of shortchain fatty acids in the interplay between diet, gut microbiota, and host energy metabolism. J Lipid Res 54: 2325-2340.

Deroanne CF, Bonjean K, Servotte S, Devy L, Colige A, Clausse N, Blacher S, Verdin E, Foidart JM, Nusgens BV, Castronovo V (2002) Histone deacetylases inhibitors as anti-angiogenic agents altering vascular endothelial growth factor signaling. Oncogene 21: 427-436.
Einhorn TA, Gerstenfeld LC (2015) Fracture healing: mechanisms and interventions. Nat Rev Rheumatol 11: 45-54.

Fan X, Li L, Ye Z, Zhou Y, Tan WS (2018) Regulation of osteogenesis of human amniotic mesenchymal stem cells by sodium butyrate. Cell Biol Int 42: 457469.

Fu X, Liu Z, Zhu C, Mou H, Kong Q (2019) Nondigestible carbohydrates, butyrate, and butyrateproducing bacteria. Crit Rev Food Sci Nutr 59: S130-S152.

Furusawa Y, Obata Y, Fukuda S, Endo TA, Nakato G, Takahashi D, Nakanishi Y, Uetake C, Kato K, Kato T, Takahashi M, Fukuda NN, Murakami S, Miyauchi E, Hino S, Atarashi K, Onawa S, Fujimura Y, Lockett T, Clarke JM, Topping DL, Tomita M, Hori S, Ohara O, Morita T, Koseki H, Kikuchi J, Honda K, Hase K, Ohno H (2013) Commensal microbe-derived butyrate induces the differentiation of colonic regulatory $\mathrm{T}$ cells. Nature 504: 446-450.

Gan Y, Shen YH, Wang J, Wang X, Utama B, Wang J, Wang XL (2005) Role of histone deacetylation in cell-specific expression of endothelial nitric-oxide synthase. J Biol Chem 280: 16467-16475.

Garrison JC, Peterson P, Uyeki EM (1989) Computer-based image analysis of cartilage differentiation in embryonic limb bud micromass cultures. J Microsc 156: 353-361.

Ghodke-Puranik Y, Thorn CF, Lamba JK, Leeder JS, Song W, Birnbaum AK, Altman RB, Klein TE (2013) Valproic acid pathway: pharmacokinetics and pharmacodynamics. Pharmacogenet Genomics 23: 236-241.

Gredes T, Gedrange T, Hinuber C, Gelinsky M, Kunert-Keil C (2015) Histological and molecularbiological analyses of poly(3-hydroxybutyrate) (PHB) patches for enhancement of bone regeneration. Ann Anat 199: 36-42.

Guntur AR, Rosen CJ (2013) IGF-1 regulation of key signaling pathways in bone. Bonekey Rep 2: 437. DOI: 10.1038/bonekey.2013.171.

Gurav A, Sivaprakasam S, Bhutia YD, Boettger T, Singh N, Ganapathy V (2015) Slc5a8, a Na+-coupled high-affinity transporter for short-chain fatty acids, is a conditional tumour suppressor in colon that protects against colitis and colon cancer under lowfibre dietary conditions. Biochem J 469: 267-278.

Guss JD, Taylor E, Rouse Z, Roubert S, Higgins $\mathrm{CH}$, Thomas CJ, Baker SP, Vashishth D, Donnelly E, Shea MK, Booth SL, Bicalho RC, Hernandez CJ (2019) The microbial metagenome and bone tissue composition in mice with microbiome-induced reductions in bone strength. Bone 127: 146-154.

Haas NP (2000) [Callus modulation-fiction or reality?]. Chirurg 71: 987-988.

Hagan T, Cortese M, Rouphael N, Boudreau C, Linde C, Maddur MS, Das J, Wang H, Guthmiller J, Zheng NY, Huang M, Uphadhyay AA, Gardinassi L, Petitdemange C, McCullough MP, Johnson SJ, Gill K, Cervasi B, Zou J, Bretin A, Hahn M, Gewirtz AT, 
Bosinger SE, Wilson PC, Li S, Alter G, Khurana S, Golding H, Pulendran B (2019) Antibiotics-driven gut microbiome perturbation alters immunity to vaccines in humans. Cell 178: 1313-1328.

Hernandez CJ (2017) The microbiome and bone and joint disease. Curr Rheumatol Rep 19: 77. DOI: 10.1007/s11926-017-0705-1.

Hernandez CJ, Guss JD, Luna M, Goldring SR (2016) Links between the microbiome and bone. J Bone Miner Res 31: 1638-1646.

Hernandez RK, Do TP, Critchlow CW, Dent RE, Jick SS (2012) Patient-related risk factors for fracturehealing complications in the United Kingdom General Practice Research Database. Acta Orthop 83: 653-660.

Hoff P, Gaber T, Strehl C, Schmidt-Bleek K, Lang A, Huscher D, Burmester GR, Schmidmaier G, Perka C, Duda GN, Buttgereit F (2016) Immunological characterization of the early human fracture hematoma. Immunol Res 64: 1195-1206.

Hui W, Yu D, Cao Z, Zhao X (2019) Butyrate inhibit collagen-induced arthritis via Treg/IL-10/Th17 axis. Int Immunopharmacol 68: 226-233.

Husted AS, Trauelsen M, Rudenko O, Hjorth SA, Schwartz TW (2017) GPCR-mediated signaling of metabolites. Cell Metab 25: 777-796.

Ibarra M, Vazquez M, Fagiolino P, Derendorf H (2013) Sex related differences on valproic acid pharmacokinetics after oral single dose. J Pharmacokinet Pharmacodyn 40: 479-486.

Iizuka N, Morita A, Kawano C, Mori A, Sakamoto K, Kuroyama M, Ishii K, Nakahara T (2018) Antiangiogenic effects of valproic acid in a mouse model of oxygen-induced retinopathy. J Pharmacol Sci 138: 203-208.

Imoto Y, Kato A, Takabayashi T, Sakashita M, Norton JE, Suh LA, Carter RG, Weibman AR, Hulse KE, Stevens W, Harris KE, Peters AT, Grammer LC, Tan BK, Welch K, Conley DB, Kern RC, Fujieda S, Schleimer RP (2018) Short-chain fatty acids induce tissue plasminogen activator in airway epithelial cells via GPR41\&43. Clin Exp Allergy 48: 544-554.

Iwami K, Moriyama T (1993) Effects of short chain fatty acid, sodium butyrate, on osteoblastic cells and osteoclastic cells. Int J Biochem 25: 1631-1635.

Jeng JH, Chan CP, Ho YS, Lan WH, Hsieh CC, Chang MC (1999) Effects of butyrate and propionate on the adhesion, growth, cell cycle kinetics, and protein synthesis of cultured human gingival fibroblasts. J Periodontol 70: 1435-1442.

Ji J, Shu D, Zheng M, Wang J, Luo C, Wang Y, Guo F, Zou X, Lv X, Li Y, Liu T, Qu H (2016) Microbial metabolite butyrate facilitates M2 macrophage polarization and function. Sci Rep 6: 24838. DOI: 10.1038/srep24838.

Jones RM, Mulle JG, Pacifici R (2018) Osteomicrobiology: the influence of gut microbiota on bone in health and disease. Bone 115: 59-67.

Jukes TH, Williams WL (1953) Nutritional effects of antibiotics. Pharmacol Rev 5: 381-420.

Jung HM, Song GA, Lee YK, Baek JH, Ryoo HM, Kim GS, Choung PH, Woo KM (2010) Modulation of the resorption and osteoconductivity of alphacalcium sulfate by histone deacetylase inhibitors. Biomaterials 31: 29-37.

Karahaliloglu Z, Ercan B, Taylor EN, Chung S, Denkbas EB, Webster TJ (2015) Antibacterial nanostructured polyhydroxybutyrate membranes for guided bone regeneration. J Biomed Nanotechnol 11: 2253-2263.

Karna E, Trojan S, Palka JA (2009) The mechanism of butyrate-induced collagen biosynthesis in cultured fibroblasts. Acta Pol Pharm 66: 229-233.

Katono T, Kawato T, Tanabe N, Suzuki N, Iida T, Morozumi A, Ochiai K, Maeno M (2008) Sodium butyrate stimulates mineralized nodule formation and osteoprotegerin expression by human osteoblasts. Arch Oral Biol 53: 903-909.

Khan S, Jena G (2014) Sodium butyrate, a HDAC inhibitor ameliorates eNOS, iNOS and TGF-beta1induced fibrogenesis, apoptosis and DNA damage in the kidney of juvenile diabetic rats. Food Chem Toxicol 73: 127-139.

Ko FC, Sumner DR (2020) How faithfully does intramembranous bone regeneration recapitulate embryonic skeletal development? Dev Dyn 250: $377-$ 392.

Koh A, De Vadder F, Kovatcheva-Datchary P, Backhed F (2016) From dietary fiber to host physiology: short-chain fatty acids as key bacterial metabolites. Cell 165: 1332-1345.

Kooistra T, van den Berg J, Tons A, Platenburg G, Rijken DC, van den Berg E (1987) Butyrate stimulates tissue-type plasminogen-activator synthesis in cultured human endothelial cells. Biochem J 247: 605-612.

Kotlinowski J,JozkowiczA(2016) PPAR gamma and angiogenesis: endothelial cells perspective. J Diabetes Res 2016: 8492353. DOI: 10.1155/2016/8492353.

Kovach TK, Dighe AS, Lobo PI, Cui Q (2015) Interactions between MSCs and immune cells: implications for bone healing. J Immunol Res 2015: 752510. DOI: 10.1155/2015/752510.

Kurita-Ochiai T, Ochiai K, Fukushima K (2001) Butyric acid-induced T-cell apoptosis is mediated by caspase- 8 and -9 activation in a Fas-independent manner. Clin Diagn Lab Immunol 8: 325-332.

Kurita-Ochiai T, Seto S, Suzuki N, Yamamoto M, Otsuka K, Abe K, Ochiai K (2008) Butyric acid induces apoptosis in inflamed fibroblasts. J Dent Res 87: 51-55.

Li JY, Chassaing B, Tyagi AM, Vaccaro C, Luo T, Adams J, Darby TM, Weitzmann MN, Mulle JG, Gewirtz AT, Jones RM, Pacifici R (2016) Sex steroid deficiency-associated bone loss is microbiota dependent and prevented by probiotics. J Clin Invest 126: 2049-2063.

Li JY, Yu M, Pal S, Tyagi AM, Dar H, Adams J, Weitzmann MN, Jones RM, Pacifici R (2020) Parathyroid hormone-dependent bone formation requires butyrate production by intestinal microbiota. J Clin Invest 130: 1767-1781.

Li L, Rao S, Cheng Y, Zhuo X, Deng C, Xu N, Zhang H, Yang L (2019) Microbial osteoporosis: The 
interplay between the gut microbiota and bones via host metabolism and immunity. Microbiologyopen 8: e00810. DOI: 10.1002/mbo3.810.

Li M, van Esch B, Wagenaar GTM, Garssen J, Folkerts G, Henricks PAJ (2018) Pro- and antiinflammatory effects of short chain fatty acids on immune and endothelial cells. Eur J Pharmacol 831: 52-59.

Lin L, Zhang J (2017) Role of intestinal microbiota and metabolites on gut homeostasis and human diseases. BMC Immunol 18: 2. DOI: 10.1186/s12865016-0187-3.

Liu H, Wang J, He T, Becker S, Zhang G, Li D, Ma X (2018) Butyrate: a double-edged sword for health? Adv Nutr 9: 21-29.

Liu JH, Yue T, Luo ZW, Cao J, Yan ZQ, Jin L, Wan TF, Shuai CJ, Wang ZG, Zhou Y, Xu R, Xie H (2020) Akkermansia muciniphila promotes type $\mathrm{H}$ vessel formation and bone fracture healing by reducing gut permeability and inflammation. Dis Model Mech 13. DOI: $10.1242 / \mathrm{dmm} .043620$.

Lobel L, Garrett WS (2019) Butyrate makes macrophages "go nuclear" against bacterial pathogens. Immunity 50: 275-278.

Loffler J, Sass FA, Filter S, Rose A, Ellinghaus A, Duda GN, Dienelt A (2019) Compromised bone healing in aged rats is associated with impaired M2 macrophage function. Front Immunol 10: 2443. DOI: 10.3389/fimmu.2019.02443.

Louis P, Young P, Holtrop G, Flint HJ (2010) Diversity of human colonic butyrate-producing bacteria revealed by analysis of the butyrylCoA:acetate CoA-transferase gene. Environ Microbiol 12: 304-314.

Lucas S, Omata Y, Hofmann J, Bottcher M, Iljazovic A, Sarter K, Albrecht O, Schulz O, Krishnacoumar B, Kronke G, Herrmann M, Mougiakakos D, Strowig T, Schett G, Zaiss MM (2018) Short-chain fatty acids regulate systemic bone mass and protect from pathological bone loss. Nat Commun 9: 55. DOI: 10.1038/s41467-017-02490-4.

Luu M, Visekruna A (2019) Short-chain fatty acids: bacterial messengers modulating the immunometabolism of T cells. Eur J Immunol 49: 842-848.

Maeshige N, Torii K, Tabuchi H, Imai M, Koga Y, Uemura M, Aoyama-Ishikawa M, Miyoshi M, Fujino H, Terashi H, Usami M (2019) Inhibitory effects of short-chain fatty acids and $\omega-3$ polyunsaturated fatty acids on profibrotic factors in dermal fibroblasts. Eplasty 19: e4.

Marcus RDD, Bouxsein ML (2013) The nature of osteoporosis. In: Osteoporosis. Editors: Marcus RFD, Dempster DW, Luckey M, Cauley JA. Academic Press. pp: 21-30.

Melhem H, Kaya B, Ayata CK, Hruz P, Niess JH (2019) Metabolite-sensing G protein-coupled receptors connect the diet-microbiota-metabolites axis to inflammatory bowel disease. Cells 8: 450. DOI: 10.3390/cells8050450.
Mignemi NA, Yuasa M, Baker CE, Moore SN, Ihejirika RC, Oelsner WK, Wallace CS, Yoshii T, Okawa A, Revenko AS, MacLeod AR, Bhattacharjee G, Barnett JV, Schwartz HS, Degen JL, Flick MJ, Cates JM, Schoenecker JG (2017) Plasmin prevents dystrophic calcification after muscle injury. J Bone Miner Res 32: 294-308.

Morgan EF, De Giacomo A, Gerstenfeld LC (2014) Overview of skeletal repair (fracture healing and its assessment). Methods Mol Biol 1130: 13-31.

Morrison DJ, Preston T (2016) Formation of short chain fatty acids by the gut microbiota and their impact on human metabolism. Gut Microbes 7: 189200.

Muire PJ, Mangum LH, Wenke JC (2020) Time course of immune response and immunomodulation during normal and delayed healing of musculoskeletal wounds. Front Immunol 11: 1056. DOI: 10.3389/ fimmu.2020.01056.

Ogawa H, Rafiee P, Fisher PJ, Johnson NA, Otterson MF, Binion DG (2003) Sodium butyrate inhibits angiogenesis of human intestinal microvascular endothelial cells through COX-2 inhibition. FEBS Lett 554: 88-94.

Oliphant K, Allen-Vercoe E (2019) Macronutrient metabolism by the human gut microbiome: major fermentation by-products and their impact on host health. Microbiome 7: 91. DOI: 10.1186/s40168-0190704-8.

Pacifici R (2018) Bone remodeling and the microbiome. Cold Spring Harb Perspect Med 8: a031203. DOI: 10.1101/cshperspect.a031203.

Parada Venegas D, De la Fuente MK, Landskron G, Gonzalez MJ, Quera R, Dijkstra G, Harmsen HJM, Faber KN, Hermoso MA (2019) Corrigendum: Short chain fatty acids (SCFAs)-mediated gut epithelial and immune regulation and its relevance for inflammatory bowel diseases. Front Immunol 10: 1486. DOI: 10.3389/fimmu.2019.01486.

Paradis FH, Hales BF (2013) Exposure to valproic acid inhibits chondrogenesis and osteogenesis in mid-organogenesis mouse limbs. Toxicol Sci 131: 234-241.

Pirozzi C, Francisco V, Guida FD, Gomez R, Lago F, Pino J, Meli R, Gualillo O (2018) Butyrate modulates inflammation in chondrocytes via GPR43 receptor. Cell Physiol Biochem 51: 228-243.

Ragsdale SW, Pierce E (2008) Acetogenesis and the Wood-Ljungdahl pathway of $\mathrm{CO}_{2}$ fixation. Biochim Biophys Acta 1784: 1873-1898.

Rahman MM, Kukita A, Kukita T, Shobuike T, Nakamura T, Kohashi O (2003) Two histone deacetylase inhibitors, trichostatin A and sodium butyrate, suppress differentiation into osteoclasts but not into macrophages. Blood 101: 3451-3459.

Ramos MG, Rabelo FL, Duarte T, Gazzinelli RT, Alvarez-Leite JI (2002) Butyrate induces apoptosis in murine macrophages via caspase-3, but independent of autocrine synthesis of tumor necrosis factor and nitric oxide. Braz J Med Biol Res 35: 161-173. 
Ratajczak W, Ryl A, Mizerski A, Walczakiewicz K, Sipak O, Laszczynska M (2019) Immunomodulatory potential of gut microbiome-derived short-chain fatty acids (SCFAs). Acta Biochim Pol 66: 1-12.

Reinke S, Geissler S, Taylor WR, Schmidt-Bleek K, Juelke K, Schwachmeyer V, Dahne M, Hartwig T, Akyuz L, Meisel C, Unterwalder N, Singh NB, Reinke P, Haas NP, Volk HD, Duda GN (2013) Terminally differentiated $\mathrm{CD}^{+} \mathrm{T}$ cells negatively affect bone regeneration in humans. Sci Transl Med 5: 177ra136. DOI: 10.1126/scitranslmed.3004754.

Roberts JL, Liu G, Darby TM, Fernandes LM, Diaz-Hernandez ME, Jones RM, Drissi H (2020) Bifidobacterium adolescentis supplementation attenuates fracture-induced systemic sequelae. Biomed Pharmacother 132: 110831. DOI: 10.1016/j. biopha.2020.110831.

Rodriguez V, Rivoira M, Marchionatti A, Perez A, Tolosa de Talamoni N (2013) Ursodeoxycholic and deoxycholic acids: a good and a bad bile acid for intestinal calcium absorption. Arch Biochem Biophys 540: 19-25.

Rossig L, Li H, Fisslthaler B, Urbich C, Fleming I, Forstermann U, Zeiher AM, Dimmeler S (2002) Inhibitors of histone deacetylation downregulate the expression of endothelial nitric oxide synthase and compromise endothelial cell function in vasorelaxation and angiogenesis. Circ Res 91: 837-844.

Rusoff LL FJ, Hyde CE, Crown RM, Gall LS (1954) Parenteral administration of aureomycin to young calves with a note on mode of action. J Dairy Sci 37: 488-497.

Schepper JD, Collins F, Rios-Arce ND, Kang HJ, Schaefer L, Gardinier JD, Raghuvanshi R, Quinn RA, Britton R, Parameswaran N, McCabe LR (2020) Involvement of the gut microbiota and barrier function in glucocorticoid-induced osteoporosis. J Bone Miner Res 35: 801-820.

Schepper JD, Collins FL, Rios-Arce ND, Raehtz S, Schaefer L, Gardinier JD, Britton RA, Parameswaran N, McCabe LR (2019) Probiotic Lactobacillus reuteri prevents postantibiotic bone loss by reducing intestinal dysbiosis and preventing barrier disruption. J Bone Miner Res 34: 681-698.

Schlundt C, El Khassawna T, Serra A, Dienelt A, Wendler S, Schell H, van Rooijen N, Radbruch A, Lucius R, Hartmann S, Duda GN, Schmidt-Bleek K (2018) Macrophages in bone fracture healing: their essential role in endochondral ossification. Bone 106: 78-89.

Schmidt-Bleek K, Kwee BJ, Mooney DJ, Duda GN (2015) Boon and bane of inflammation in bone tissue regeneration and its link with angiogenesis. Tissue Eng Part B Rev 21: 354-364.

Schroeder TM, Westendorf JJ (2005) Histone deacetylase inhibitors promote osteoblast maturation. J Bone Miner Res 20: 2254-2263.

Schulthess J, Pandey S, Capitani M, Rue-Albrecht KC, Arnold I, Franchini F, Chomka A, Ilott NE, Johnston DGW, Pires E, McCullagh J, Sansom SN, Arancibia-Carcamo CV, Uhlig HH, Powrie F (2019)
The short chain fatty acid butyrate imprints an antimicrobial program in macrophages. Immunity 50: 432-445.

Selkrig J, Wong P, Zhang X, Pettersson S (2014) Metabolic tinkering by the gut microbiome: implications for brain development and function. Gut Microbes 5: 369-380.

Shavandi A, Saeedi P, Gerard P, Jalalvandi E, Cannella D, Bekhit AE (2020) The role of microbiota in tissue repair and regeneration. J Tissue Eng Regen Med 14: 539-555.

Shi N, Li N, Duan X, Niu H (2017) Interaction between the gut microbiome and mucosal immune system. Mil Med Res 4: 14. DOI: 10.1186/s40779-0170122-9.

Shirasugi M, Nishioka K, Yamamoto T, Nakaya T, Kanamura N (2017) Normal human gingival fibroblasts undergo cytostasis and apoptosis after long-term exposure to butyric acid. Biochem Biophys Res Commun 482: 1122-1128.

Shishatskaya EI, Kamendov IV, Starosvetsky SI, Vinnik YS, Markelova NN, Shageev AA, Khorzhevsky VA, Peryanova OV, Shumilova AA (2014) An in vivo study of osteoplastic properties of resorbable poly-3hydroxybutyrate in models of segmental osteotomy and chronic osteomyelitis. Artif Cells Nanomed Biotechnol 42: 344-355.

Shreiner AB, Kao JY, Young VB (2015) The gut microbiome in health and in disease. Curr Opin Gastroenterol 31: 69-75.

Shumilova AA, Myltygashev MP, Kirichenko AK, Nikolaeva ED, Volova TG, Shishatskaya EI (2017) Porous 3D implants of degradable poly-3hydroxybutyrate used to enhance regeneration of rat cranial defect. J Biomed Mater Res A 105: 566-577.

Sjogren K, Engdahl C, Henning P, Lerner UH, Tremaroli V, Lagerquist MK, Backhed F, Ohlsson C (2012) The gut microbiota regulates bone mass in mice. J Bone Miner Res 27: 1357-1367.

Sun G, Wang Y, Ti Y, Wang J, Zhao J, Qian H (2017a) Regulatory B cell is critical in bone union process through suppressing proinflammatory cytokines and stimulating Foxp3 in Treg cells. Clin Exp Pharmacol Physiol 44: 455-462.

Sun M, Wu W, Liu Z, Cong Y (2017b) Microbiota metabolite short chain fatty acids, GPCR, and inflammatory bowel diseases. J Gastroenterol 52: 1-8.

Takigawa S, Sugano N, Nishihara R, Koshi R, Murai M, Yoshinuma N, Ochiai K, Ito K (2008) The effect of butyric acid on adhesion molecule expression by human gingival epithelial cells. J Periodontal Res 43: 386-390.

Tokiwa Y, Calabia BP (2004) Degradation of microbial polyesters. Biotechnol Lett 26: 1181-1189.

Tyagi AM, Yu M, Darby TM, Vaccaro C, Li JY, Owens JA, Hsu E, Adams J, Weitzmann MN, Jones RM, Pacifici R (2018) The microbial metabolite butyrate stimulates bone formation via $\mathrm{T}$ regulatory cell-mediated regulation of WNT10B expression. Immunity 49: 1116-1131. 
Tzioupis C, Giannoudis PV (2007) Prevalence of long-bone non-unions. Injury 38 Suppl 2: S3-9.

Usami M, Kishimoto K, Ohata A, Miyoshi M, Aoyama M, Fueda Y, Kotani J (2008) Butyrate and trichostatin A attenuate nuclear factor kappaB activation and tumor necrosis factor alpha secretion and increase prostaglandin E2 secretion in human peripheral blood mononuclear cells. Nutr Res 28: 321-328.

Vinolo MA, Ferguson GJ, Kulkarni S, Damoulakis G, Anderson K, Bohlooly YM, Stephens L, Hawkins PT, Curi R (2011) SCFAs induce mouse neutrophil chemotaxis through the GPR43 receptor. PLoS One 6: e21205. DOI: 10.1371/journal.pone.0021205.

Wells JM, Brummer RJ, Derrien M, MacDonald TT, Troost F, Cani PD, Theodorou V, Dekker J, Meheust A, de Vos WM, Mercenier A, Nauta A, GarciaRodenas CL (2017) Homeostasis of the gut barrier and potential biomarkers. Am J Physiol Gastrointest Liver Physiol 312: G171-G193.

Woo KM, Jung HM, Oh JH, Rahman SU, Kim SM, Baek JH, Ryoo HM (2015) Synergistic effects of dimethyloxalylglycine and butyrate incorporated into alpha-calcium sulfate on bone regeneration. Biomaterials 39: 1-14.

Xu X, Jia X, Mo L, Liu C, Zheng L, Yuan Q, Zhou $X$ (2017) Intestinal microbiota: a potential target for the treatment of postmenopausal osteoporosis. Bone Res 5: 17046. DOI: 10.1038/boneres.2017.46.

Yacowitz ERaH (1954) Effect of penicillin on growth and bone ash of chicks fed different levels of vitamin D and phosphorus. Poulty Sci 33: 262-265.

Yan J, Charles JF (2017) Gut microbiome and bone: to build, destroy, or both? Curr Osteoporos Rep 15: 376-384.

Yan J, Herzog JW, Tsang K, Brennan CA, Bower MA, Garrett WS, Sartor BR, Aliprantis AO, Charles JF (2016) Gut microbiota induce IGF-1 and promote bone formation and growth. Proc Natl Acad Sci U S A 113: E7554-E7563.

Yan J, Takakura A, Zandi-Nejad K, Charles JF (2018) Mechanisms of gut microbiota-mediated bone remodeling. Gut Microbes 9: 84-92.

Yang S, Ding W, Feng D, Gong H, Zhu D, Chen B, Chen J (2015) Loss of B cell regulatory function is associated with delayed healing in patients with tibia fracture. APMIS 123: 975-985.

Yi T, Baek JH, Kim HJ, Choi MH, Seo SB, Ryoo HM, Kim GS, Woo KM (2007) Trichostatin A-mediated upregulation of p21(WAF1) contributes to osteoclast apoptosis. Exp Mol Med 39: 213-221.

Young DA, Lakey RL, Pennington CJ, Jones D, Kevorkian L, Edwards DR, Cawston TE, Clark IM (2005) Histone deacetylase inhibitors modulate metalloproteinase gene expression in chondrocytes and block cartilage resorption. Arthritis Res Ther 7: R503-512.

Yu M, Malik Tyagi A, Li JY, Adams J, Denning TL, Weitzmann MN, Jones RM, Pacifici R (2020) PTH induces bone loss via microbial-dependent expansion of intestinal $\mathrm{TNF}(+) \mathrm{T}$ cells and Th17 cells. Nat Commun 11: 468. DOI: 10.1038/s41467-019-14148-4.

Zaiss MM, Jones RM, Schett G, Pacifici R (2019) The gut-bone axis: how bacterial metabolites bridge the distance. J Clin Invest 129: 3018-3028.

Zhang J, Lu Y, Wang Y, Ren X, Han J (2018) The impact of the intestinal microbiome on bone health. Intractable Rare Dis Res 7: 148-155.

Zhou D, Fan JG (2019) Microbial metabolites in non-alcoholic fatty liver disease. World J Gastroenterol 25: 2019-2028.

Zura R, Mehta S, Della Rocca GJ, Steen RG (2016) Biological risk factors for nonunion of bone fracture. JBJS Rev 4. DOI: 10.2106/JBJS.RVW.O.00008.

\section{Discussion with Reviewers}

Reviewer 1: What are possible strategies to manipulate the gut microbiome in a way that positively influences fracture repair and/or osteointegration?

Authors: Different strategies are conceivable to manipulate the gut microbiota of fracture patients in a potential beneficial way. SCFAs can be directly given as a supplement (also termed as postbiotic delivery). This strategy has been used in different randomised control trials of inflammatory bowel disease and colitis patients (Gill et al., 2018, additional reference). Tributyrin is a butyrate pro-drug and its encapsulation reduces the unpleasant sensory characteristics of butyrate. However, no reports of its application in a clinical trial are available yet (Gill et al., 2018, additional reference). Alternatively, administration of pharmacological compounds mimicking the mechanism of action of SCFAs, can be used (e.g. HDAC inhibitors, which are already used in clinical trials as new anticancer agents).

Supplementation with prebiotics, high-fibre compounds that stimulate SCFA production, can also be a strategy. High-fibre supplementation in rheumatoid arthritis patients leads to an increase in circulating Treg cell numbers and a decrease in bone erosion marker and even improved patient-related outcomes of rheumatoid arthritis following $28 \mathrm{~d}$ of supplementation (Hager et al., 2019, additional reference). Given that bone erosion marker CTX-1 decreases in those patients, high-fibre supplementation could also be a promising strategy for fracture patients.

Reviewer 2: Prolonged periods of antibiotic administration are administered in cases where an implant or fracture site is infected. Given the possible importance of the microbiome to bone healing, should this matter be revisited?

Authors: This is indeed an important point. In addition to intravenous antibiotic administration, infected patients are likely to also receive several weeks of oral antibiotic therapy. Although many 
studies have shown that changes in the composition of the gut microbiota are associated with many diseases, including bone-associated pathologies, and intestinal dysbiosis induced by antibiotics results in bone loss and a dysregulated osteoimmune crosstalk in postpubertal skeletal development in mice (Hathaway-Schrader et al., 2019, additional reference), the impact of different antibiotic substances on the microbiome and the healing outcomes of these patients remain poorly understood. As outlined in the present review, the microbiome regulates immune cell function and many different cell types involved in bone healing, therefore, any disruption of this interaction by antibiotics could significantly affect healing outcomes in those patients. Further research investigating the consequences of antibiotic therapy on fracture healing in infected patients is of uppermost importance.

In addition to the prolonged antibiotic exposure in infected patients, all patients with operative fixation of a fracture may receive between 1-5 $d$ of PAP. Even such a short duration of antibiotics may also significantly impact the microbiome. Given that the number of patients receiving PAP will greatly outweigh those receiving prolonged systemic antibiotic therapy, this should also be considered as a target for intervention in all patients, not only infected patients.

FMT could be an interesting approach to intervene and avoid potential deleterious effects of antibiotic therapy. Stool from either a healthy donor or from the patients themselves (which was stored away before antibiotic therapy) is transferred or re-implanted, respectively, into the colon of the patient. FMT was already successfully used for treatment of primary Clostridium difficile infection (Juul et al., 2018, additional reference) and ulcerative colitis (Blanchaert et al., 2019, additional reference). Although FMT seems to be a promising therapy, further research, especially with larger cohorts are needed to confirm and determine the optimal FMT procedure, which would allow expanding the application of FMT therapy to treat not only gut-associated morbidities but also other diseases, including delayed bone healing.

\section{Additional References}

Blanchaert C, Strubbe B, Peeters H (2019) Fecal microbiota transplantation in ulcerative colitis. Acta Gastroenterol Belg 82: 519-528.

Gill PA, van Zelm MC, Muir JG, Gibson PR (2018) Review article: short chain fatty acids as potential therapeutic agents in human gastrointestinal and inflammatory disorders. Aliment Pharmacol Ther 48: 15-34.

Hager J, Bang H, Hagen M, Frech $M$, Trager $\mathrm{P}$, Sokolova MV, Steffen U, Tascilar K, Sarter K, Schett G, Rech J, Zaiss MM (2019) The role of dietary fiber in rheumatoid arthritis patients: a feasibility study. Nutrients 11: 2392. DOI: 10.3390/nu11102392.

Hathaway-Schrader JD, Steinkamp HM, Chavez MB, Poulides NA, Kirkpatrick JE, Chew ME, Huang E, Alekseyenko AV, Aguirre JI, Novince CM (2019) Antibiotic perturbation of gut microbiota dysregulates osteoimmune cross talk in postpubertal skeletal development. Am J Pathol 189: 370-390.

Juul FE, Garborg K, Bretthauer M, Skudal H, Oines MN, Wiig H, Rose O, Seip B, Lamont JT, Midtvedt T, Valeur J, Kalager M, Holme O, Helsingen L, Loberg M, Adami HO (2018) Fecal microbiota transplantation for primary clostridium difficile infection. $\mathrm{N}$ Engl J Med 378: 2535-2536.

Editor's note: The Scientific Editor responsible for this paper was Chris Evans. 